\title{
Erratum to: The Virtue Ethics of Levi Gersonides
}

\author{
Alexander Green
}

\section{DOI 10.1007/978-3-319-40820-0_7}

The original version of this book contained errors which have been corrected.

The page numbers have been corrected as below for the Index entries war and Wars of the Lord.

war

$20,33,43-45,76,108-112,114,120 \mathrm{nl} 14,12 \ln 117,127,130,134-$ $136,138-139,143-144,146,163$

Gersonides, Levi,

Wars of the Lord- 6, 8-11, 14n23, 15n29, 16n36, 16n44, 23-26, 29, 41, 50n7-10, 50n15, 52n29, 52n31, 53n34, 53n36, 53n39, 54n50, 54n57, 54n59-60, 55n65, 55n88, 57nl03, 59nl63, 60nl87, 73-74, 85n40, 86n47, 87n54, 87n56 -57, 87n61, 87n63, 87n67, 87n73, 88n74, 88n76, $88 \mathrm{n} 79,88 \mathrm{n} 82,89 \mathrm{nl} 00,95,115 \mathrm{n} 12-13,116 \mathrm{n} 21,126-128,143,148 \mathrm{nl}$, $148 \mathrm{n} 19,153 \mathrm{nl} 48,160,166,169 \mathrm{n} 17,170 \mathrm{n} 39,172 \mathrm{n} 72$

The updated online version of the original book can be found at http://dx.doi.org/10.1007/978-3-319-40820-0 